\title{
Illuminance Calculations for Stage Lighting Concept as a Tool to Improve It
}

\author{
Maksim Nasennikov \\ National University of Science and Technology "MISIS", Moscow, Russia \\ m145447@edu.misis.ru
}

\begin{abstract}
The article covers lighting design in terms of its impact on a human. After making an analysis of scientific sources on this topic, the project has been implementing with the use of 3D modeling software. The model of the concert hall of NUST "MISIS" was created, then several concepts of stage lighting were developed. We made an analysis of one concept using lighting engineering calculations. This allowed us to find out how safe developed variant of stage lighting is.
\end{abstract}

Keywords: 3D Model, Light Impact, Auditorium.

\section{Introduction}

Nowadays three-dimensional graphics is one of the most popular areas of information technology. Due to the need to model real-world situations, technologies of this area are used in various fields of human activities. Moreover, the ability to demonstrate various processes without need to be in specific place at specific moment is one of the advantages of 3D graphics.

In the framework of this work we consider the use of three-dimensional graphics in the field of lighting design in order to study the effects of light on a person during stage performances. Since light is able to affect both biological and psychological processes in the body, this is a relevant topic at the moment.

\section{Light Impact on a Human}

In 2002 David M. Berson revealed the presence of a new receptor in human eyes, which is not responsible for the formation of visual images [1, 2]. George C. Brainard in turn conducted a study where he examined dependence of melatonin level in blood on the light wavelength and found a relationship between light exposure and human circadian rhythm [2]. New elements in retina mainly transmit signals to nonvisual brain areas that regulate psychological state and neuroendocrine system of the body [1].

Copyright (C) 2020 for this paper by its authors. Use permitted under Creative Commons License Attribution 4.0 International (CC BY 4.0). 


\section{M. Nasennikov}

It was found that optical radiation with wavelengths of $430-470 \mathrm{~nm}$ affects the production of melatonin and when the eyes are exposed to light with an illuminance of 1000-2000 lux for 3 hours, phase shift is from 2 to 4 hours [3].

More intense exposure leads to more harm to the body $[4,5]$. This effect is associated with photo-oxidative damage when light exposure causes formation of reactive molecules in retina that damage surrounding molecules [4, 6]. The report of the French Agency for Food, Environmental and Occupational Health \& Safety, that was presented in 2019, confirmed harmful effects of blue light from LEDs on eyes and noted that intense exposure to blue light causes reduced visual acuity and negative phototoxic effects in retina, which can increase the risk of macular degeneration [7, 8].

Since concert lighting devices are able to generate intense light rays, the possibility of negative effects on a person during stage performance cannot be excluded.

\section{Development and Subsequent Visualization of a 3D Model of the Auditorium of NUST "MISIS"}

One of the main stages of this project was development of a 3D model of the concert hall of NUST "MISIS". Software "Blender" was chosen among other applications to do that as it has a large number of instruments for model's creation and its high-quality visualization.

\subsection{D Model Development}

The main approach that was used for creation of this 3D auditorium was polygonal modeling. A polygon is a thin small piece of an object that usually has quadrangular shape. Polygons connected by adjacent edges form a single mesh that is the shell of a certain object.

Objects with rounded shapes, such as armchairs or railings, were created with a large number of polygons, because lack of them make these models look unnatural (for example, the mesh of the armchair in the 3D auditorium consists of 11288 polygons). Other objects (walls, floor, etc.) were made using low-poly technique. In this case a small number of polygons was used to create an object because it speeds up visualization process and has almost no effect on its visual appearance (for example, the mesh of the walls in the 3D-auditorium is made of 74 polygons).

In order to arrange armchairs in the 3D concert hall function "Group Instance" was used since it needs less RAM to store information about spaced objects.

Each model of the 3D auditorium acquired its own material as soon as modeling of objects was completed (fig. 1).

Various types of maps were assigned to a material (diffuse map, normal map, height map, etc.) and the numerical values of different parameters were selected. Diffuse maps are images that were used to set the color and pattern of an object. Normal maps are images that were used to control each pixel's normal and imitate details on a surface of a model which looks like they were created by the polygons. Height maps are images that were used to provide data for surfaces where the map is responsible for rendering 
protrusions and bumps. In some cases, UV mapping was used to get a more accurate overlay of a texture on a model.

Various light sources were placed in the scene. Ies-files were used for ceiling lights since they provide accurate light parameters that are comparable to real lamps, «Spotlights» were created to imitate concert lighting that has a conical shape.

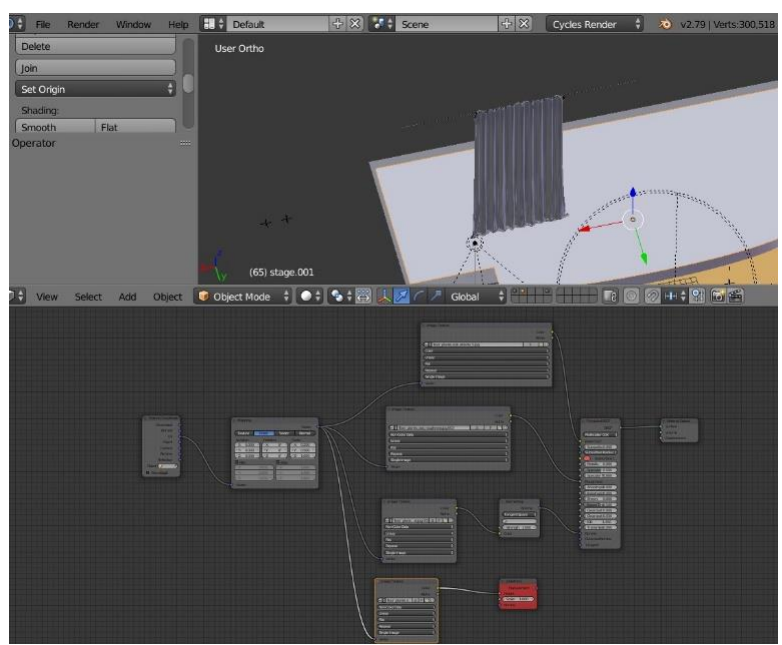

Fig. 1. Adjustment of materials in «Node Editor»

\subsection{Lighting Visualization}

Internal renderer «Cycles» was used to create high-quality visualizations of 3D auditorium of NUST "MISIS" (fig. 2).

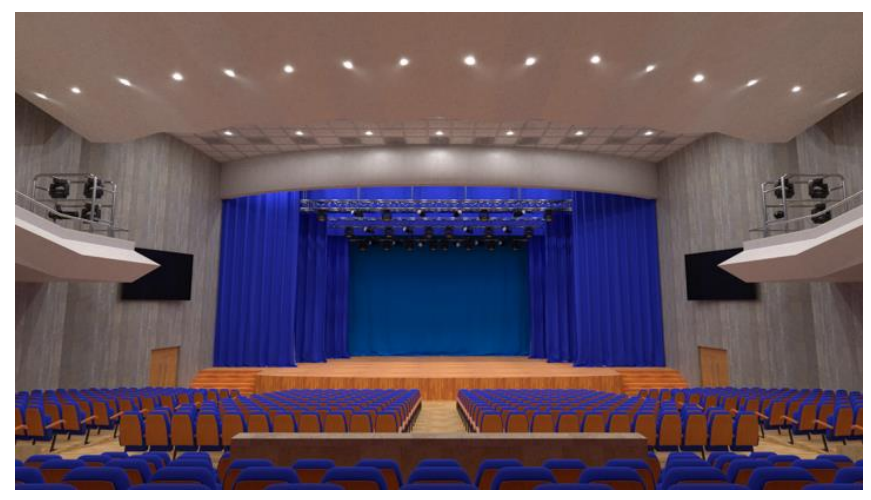

Fig. 2. Visualization of 3D concert hall of NUST "MISIS" when ceiling lighting operates

To make visualization of the auditorium of NUST "MISIS" when ceiling lights are turned on, the following values of settings for «Cycles» renderer were set [9]: 
4 M. Nasennikov

- Render - 3000 (number of samples for rendering);

- Total - 12 (maximum number of light bounces);

- Diffuse - 4 (maximum number of diffuse bounces);

- Glossy - 4 (maximum number of glossy bounces);

- Transparency - 8 (maximum number of transparency bounces);

- Transmission - 12 (maximum number of transmission bounces);

- Volume - 0 (maximum number of volume scattering bounces).

Based on the created model of the concert hall, we developed concepts of stage lighting for different events.

The main types of events that take place in the auditorium of NUST "MISIS" are entertainment formats (for example, concerts) and conferences. Therefore, stage lighting options were created for these types of activities: presenter's speech, panel discussion (several participants), dance number, music number.

Presenter's Speech (Host, Rector). In this case, attention of the audience is focused on one person, therefore it makes sense to create a contrast between dark hall and illuminated stage (fig. 3). However, in order not to make stage look too dark, the curtains are illuminated by light sources from right and left parts of the balcony and devices fixed above the stage floor.

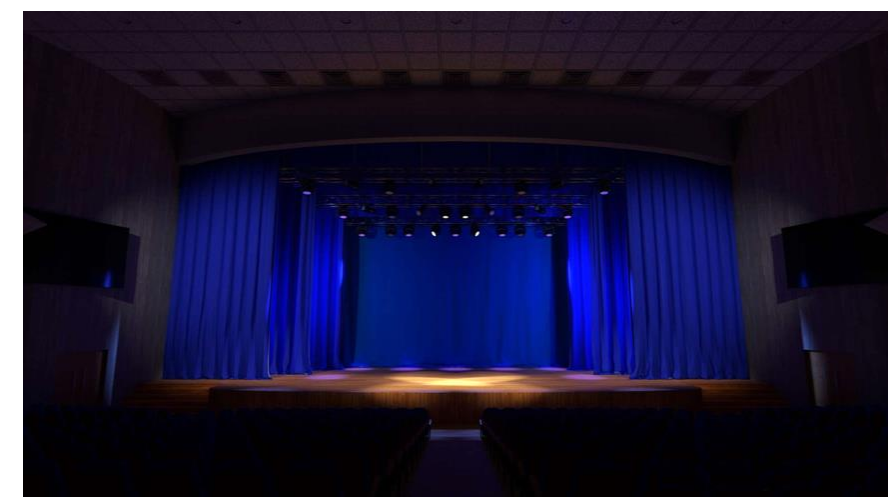

Fig. 3. Visualization of 3D auditorium of NUST "MISIS" when stage lighting operates (presenter's speech)

Panel Discussion (Several Participants). In this case, attention of the audience is focused on several people participating in a discussion (fig. 4). That is why larger area of the stage, in comparison with the previous scenario, must be illuminated. During such discussion some viewers may need light to move around the hall or make notes. For these reasons ceiling lighting operates at a certain level of brightness (not maximum). At the same time, the back of the stage can be lit with a dim light (the shade of this light differs from the color of rays directed at the speakers) to make light composition more pleasant.

Dance Number. This format of stage performance implies the use of different light sources, as well as shades of rays (fig. 5). It involves active movements of dancers that 
are supported by changes of light rays direction (narrow white rays and colored rays on the stage).

Music Number. As in the previous case, a large number of stage lighting devices are used for the song number (fig. 6). Relatively dim violet light creates a sense of volume on the stage. The artist is stand out by two light cannons located on the balcony. At the same time, dynamism is added to the performance with the help of narrow yellow rays emitted by «spot» lighting devices. Directed to the ceiling, these light beams change their position during the number, however they are not directed towards the audience.

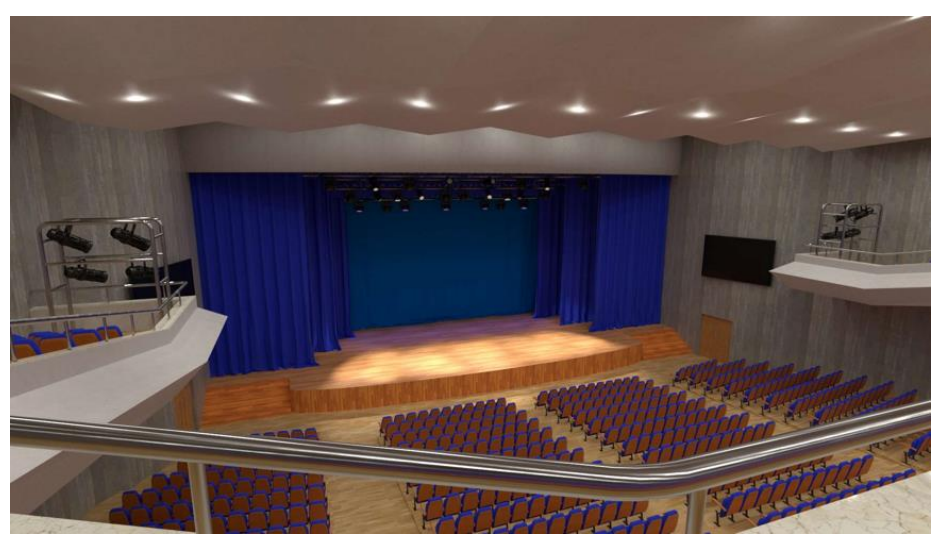

Fig. 4. Visualization of 3D auditorium of NUST "MISIS" when stage lighting operates (panel discussion)

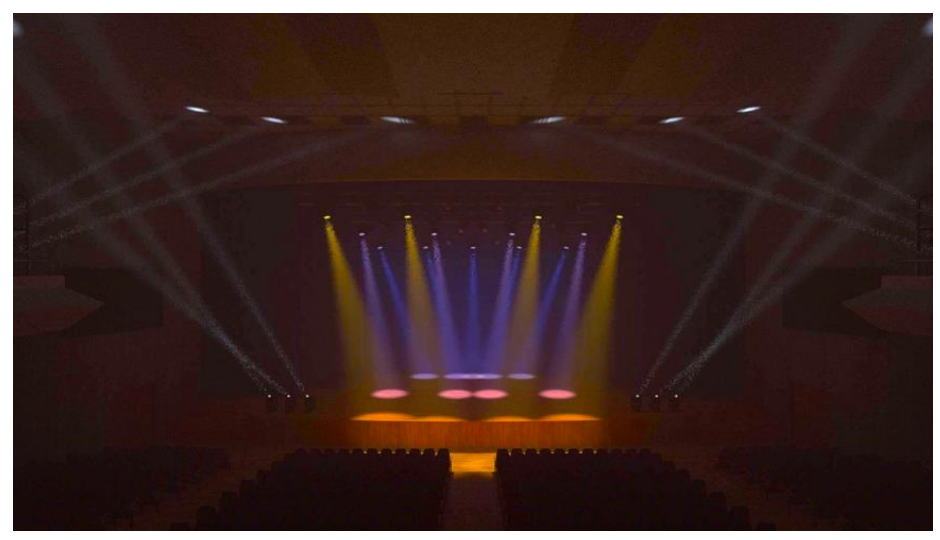

Fig. 5. Visualization of 3D auditorium of NUST "MISIS" when stage lighting operates (dance number) 
6 M. Nasennikov

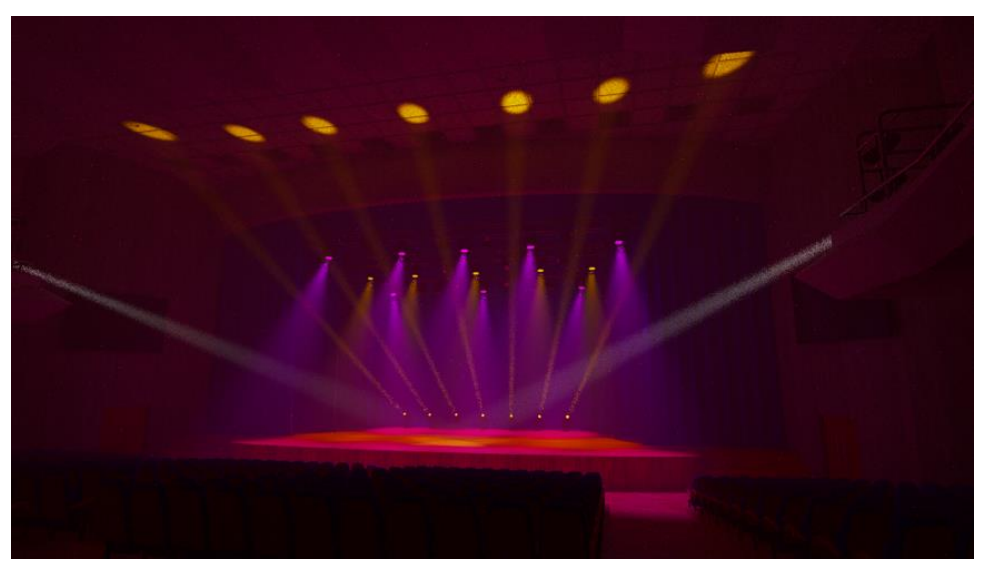

Fig. 6. Visualization of 3D auditorium of NUST "MISIS" when stage lighting operates (music number)

\section{Analysis of the Developed Version of Stage Lighting with the Use of a Specialized Software}

Among proposed concepts of stage lighting the one for the performance of a presenter was chosen for further analysis. This choice was made because stage lighting options for music and dance performances involve constant change of light beams direction, and in these cases the process of analysis can be more complicated.

\subsection{Configuring of the 3D Model in the Software "DIALux evo"}

The software "DIALux evo" was chosen to execute lighting calculations. Developed model was modified by reducing the number of polygons for objects in the auditorium (handrails, curtains, etc.) and loaded into "DIALux evo" program.

We uploaded ies-profiles of light sources into the project and set parameters of devices, including their rotation angles and position in the 3D hall.

Materials (some of which are color and some are textural) were created for various objects of the scene (walls, floor, curtains, etc.). In the settings of the material its type was selected (varnished, metallic, transparent). Reflection properties and various coefficients (reflection, transmission, refraction coefficient) were adjusted as well. A color was selected on the RGB scale for color materials, and a texture loaded into the project was selected for texture materials.

In order to simulate the presence of a real person on stage and obtain more detailed picture of light distribution, a model from the website archive3d.net (URL: https://archive3d.net/?a=download\&id=4b966ed8) was used (fig. 7). 
Illuminance Calculations for Stage Lighting Concept as a Tool to Improve It 7

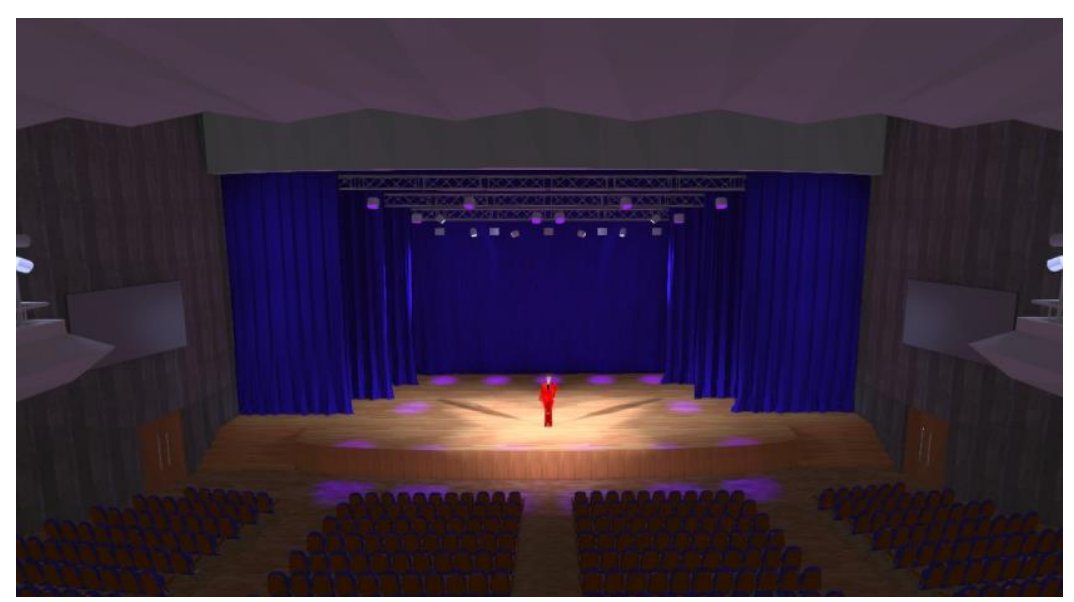

Fig. 7. Visualization of 3D auditorium of NUST "MISIS" in the software "DIALux evo" (presenter's speech)

By adjusting the colors, the visualization of surface illumination for the auditorium of NUST "MISIS" was obtained on a scale of 1 to 500 lux (fig. 8).

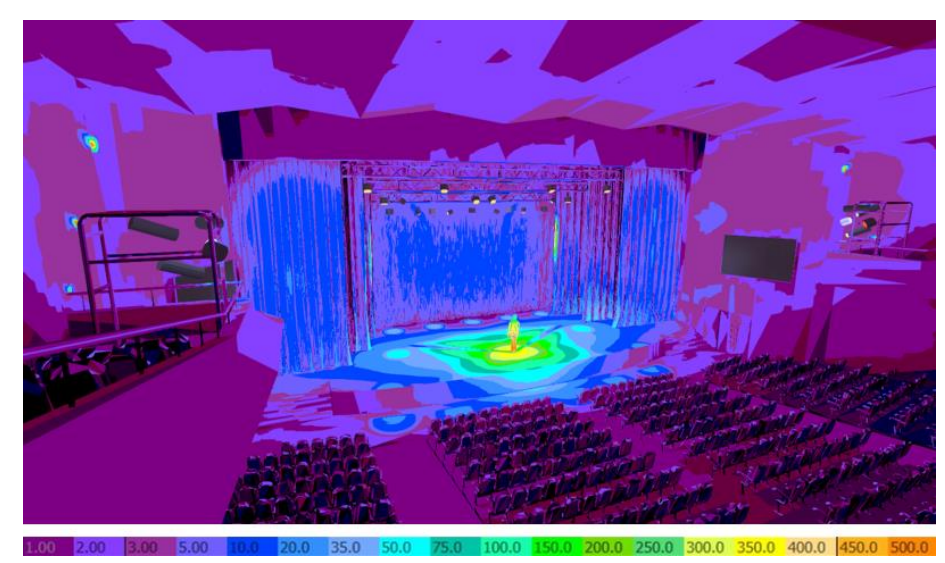

Fig. 8. Illumination model of the auditorium of NUST "MISIS" (presenter's speech)

We were using rectangular objects (type «calculation surfaces») to create illumination diagrams in various planes (horizontal, vertical). One calculated object is installed along the longitudinal axis of the auditorium being perpendicular to the stage floor, the other is also perpendicular to the stage floor being rotated at an angle of $90^{\circ}$ to the longitudinal axis. In both of these cases, semi-cylindrical illuminance is calculated since a person on stage can be considered as a cylinder (volumetric body). Only part of a person is visible in both side and front views, therefore one can be considered as half of a cylinder (fig. 9, 10). 


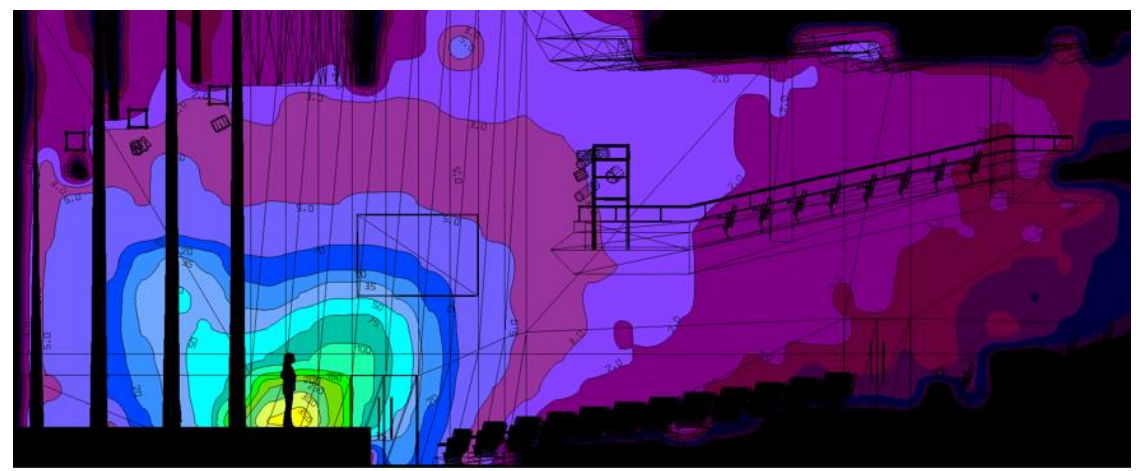

Fig. 9. Illumination diagram. Side view (the plane passes through the longitudinal axis of the hall)

Due to the fact that different events in the concert hall of NUST "MISIS" are usually recorded on cameras or broadcasted online, camera-oriented illuminance was also calculated. At the 12th row of armchairs (zone of parterre), a calculation object «camera» was installed (height to the floor is $1.3 \mathrm{~m}$ ). It was directed along the longitudinal axis of the auditorium. Two calculation planes were set perpendicular to the camera and the stage floor (the first is passing through the model of the speaker, the second is placed at the background curtain of the stage). For both of them camera-oriented illuminance was calculated (fig. 11).

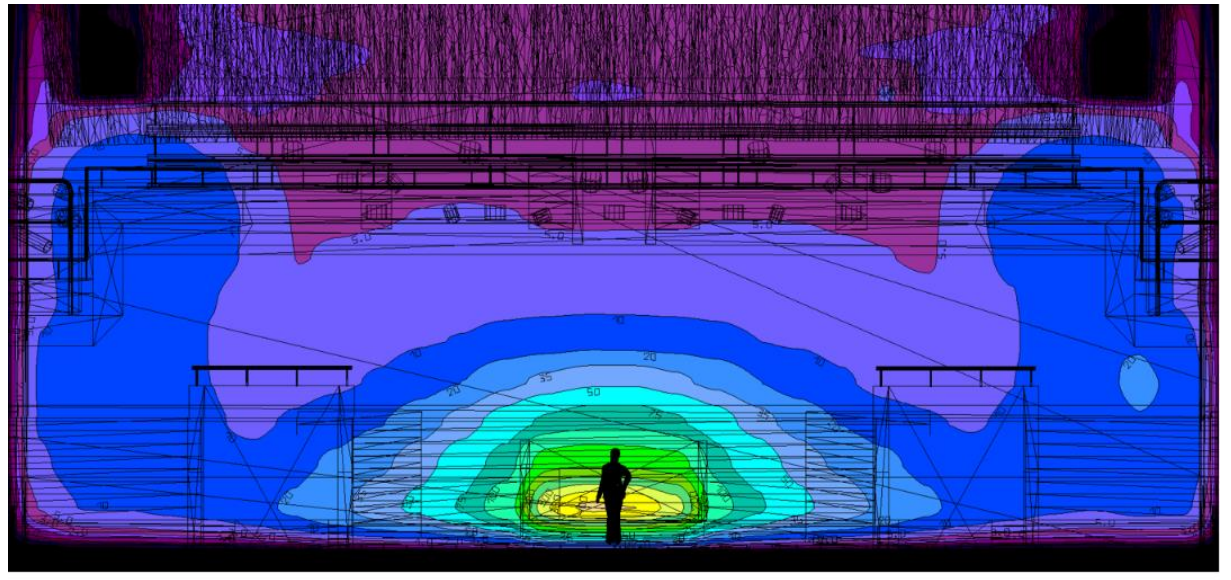

Fig. 10. Illumination diagram. Front view (the plane is perpendicular to the longitudinal axis of the hall) 
Illuminance Calculations for Stage Lighting Concept as a Tool to Improve It 9

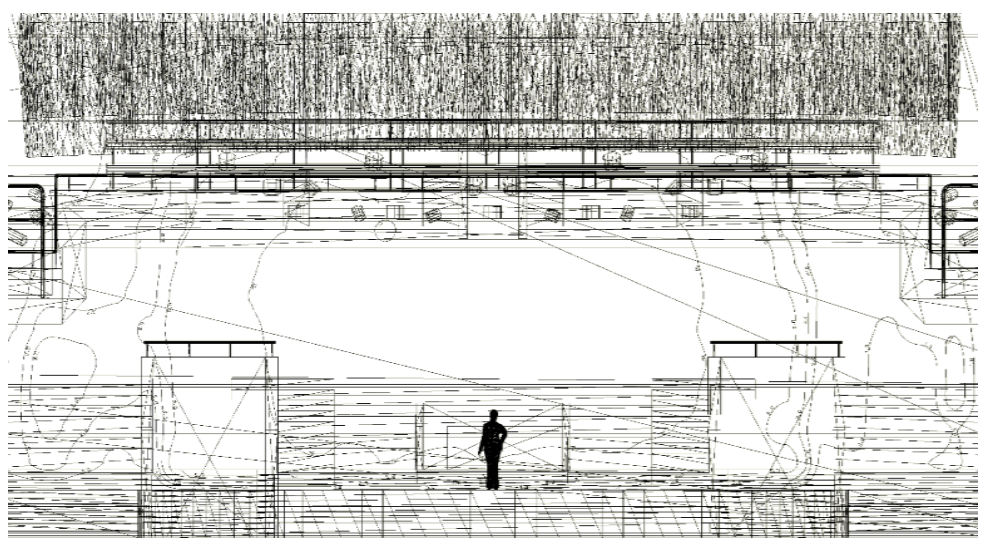

Fig. 11. Illumination diagram (camera-oriented illuminance). Front view (the plane passes through the background curtain)

Two calculation objects were placed parallel to the floor of the first row of the seats: one passes through the stage floor (fig. 12), the other is at a height of $1.75 \mathrm{~m}$ from the stage deck (fig. 13). Horizontal illuminance was set as a calculated parameter for both of them.

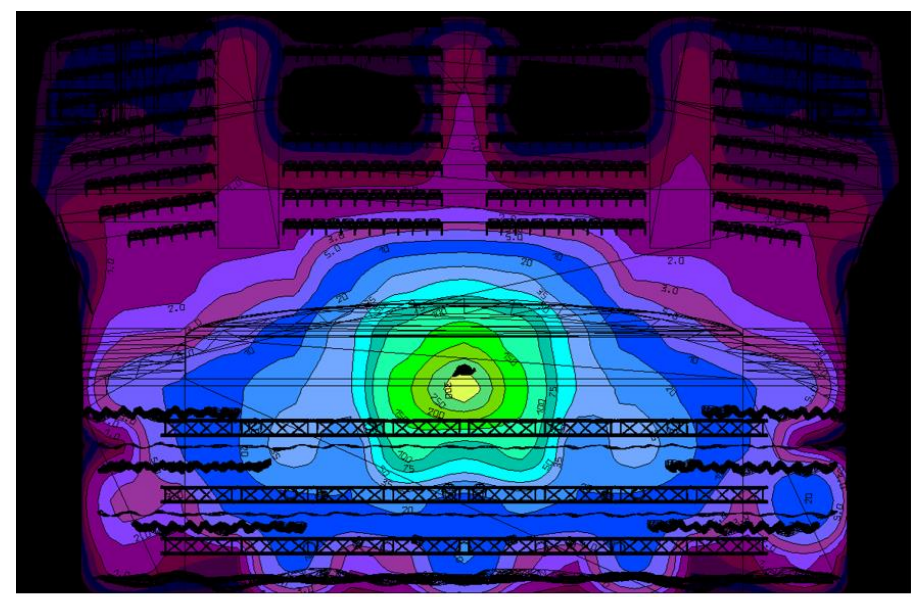

Fig. 12. Illuminance chart at the stage floor level 
10 M. Nasennikov

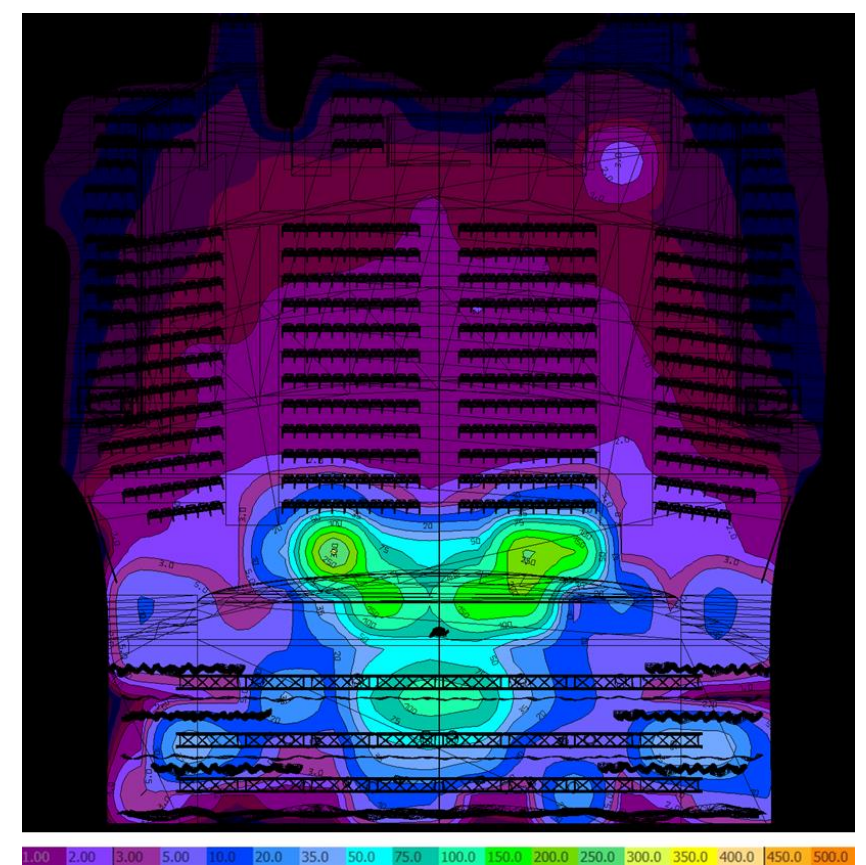

Fig. 13. Illuminance chart at a height of $1.75 \mathrm{~m}$ from the stage deck

\subsection{Criteria Analysis}

The resulting illumination values were analyzed based on the criteria.

Limiting the Level of Illumination in Different Areas of the Hall. Based on the data obtained, it was concluded that in any area of the auditorium, illuminance values are lower than 1000 lux. Values from 1 to 75 lux (at the level of the stage floor) are observed outside the stage. At the same time, values from 10 to 75 lux are detected only near the stage, and in the zone where armchairs are placed the illumination is 110 lux. Therefore, the probability of a negative effect of light on the audience decreases.

At a height of $1.75 \mathrm{~m}$ from the stage floor level, there are illuminance zones with values of 300 lux, which corresponds to the recommendations of the Russian code of rules No. 31-110-2003 (in Russian “CП 31-110-2003”), according to which the stage of the auditorium of NUST "MISIS" fits the parameters of S-1 - S-3 type (in Russian $\mathrm{C}-1-\mathrm{C}-3$ ) [10]. However, these values are observed in the plane that is parallel to the stage floor (fig. 13), and not perpendicular to it. In the side view diagram (fig. 9) illuminance of 300 lux is detected below $1.75 \mathrm{~m}$ from the stage floor. At the same time, illumination obtained in a practical way at this height has its advantages. At the model's eyes level, its value is about 75 lux (75-100 lux), and therefore the risks of blinding the presenter or injuring one's visual system are lower than at 300 lux.

Visibility of the Presenter Acting on Stage. Since the illuminance, in accordance with the calculation results, is from 100 to 400 lux at the location of the presenter, and 
is from 1 to 10 lux at the level of the background curtain, the speaker will be clearly visible from the auditorium due to this difference of values (fig. 10,11). The visualization of stage lighting (fig. 7) confirms this - the person is clearly distinguished.

Suitability of Color Composition for the Performance. Since the main purpose of using light for a speaker's performance is to provide a sufficient level of one's illumination, directed at the presenter rays have light shades (soft yellow). At the same time, there is no need to create any special atmosphere (mystery, fear, etc.). To create color contrast the background is illuminated with a dim violet light that reduces human's irritation. Yellow light is associated with warmth, coziness, and therefore, the viewer can feel more comfortable in the auditorium.

Appropriateness of the Way Lighting Devices are Used. Mixed approach of lighting is used for a speaker's performance: the person stands out with directional lighting against background soft light (diffuse lighting).

Similar lighting devices from left and right parts of the balcony are used as well as symmetrically placed light sources above the stage surface. Thanks to this relatively symmetrical picture of stage lighting is observed.

Diffused lighting on the stage is created by ETC SOURCE FOUR Zoom devices located on the sides of the balcony (diagonal lighting). Also, soft light on the stage is supported by ROBE ROBIN 600 LEDWash devices fixed above the stage floor.

The curtains are illuminated from the balcony with the use of ROBE ROBIN 1200 LEDWash.

Griven Inse 1200 MSR light sources emit light on the speaker being set at an angle to the person. It reduces the chance of one's blinding.

ROBE ROBIN 600E Spot moving heads generate violet light spots. The intensity of these rays is relatively low, therefore, despite the fact that some of them partially fall into spectator area, the risks of their negative effects on viewers are negligible (illuminance does not exceed 10 lux in the zone of the first and second rows of seats).

Since light rays emitted from the balcony are not directed at the audience, the provisions of the order of the Ministry of Culture of the Russian Federation (order No. 2 from January 6, 1998) are fulfilled in this case [11].

\section{Conclusion}

The models developed as part of this work can be used in future as a tool to prepare stage lighting design for different events.

Based on the work done, we can conclude that after creating stage lighting concept, it must be analyzed before the event will take place. Completed calculations allow us to make changes to the stage lighting, thereby avoiding violations of existing standards and recommendations. That helps to improve the lighting environment of the auditorium. 
12 M. Nasennikov

\section{References}

1. Aizenberg, J. et al.: Spravochnaya kniga po svetotekhnike (Reference Book on Lighting Engineering). 3rd edn. Znak, Moscow (2006)

2. Brainard, G. et al.: Action spectrum for melatonin regulation in humans: evidence for a novel circadian photoreceptor. Journal of Neuroscience 21(16), 6405-6412 (2001)

3. Ioffe, K.: Biologicheskoe vliyanie vidimogo sveta na organizm cheloveka (Biological effect of visible light on a human body). Lighting Engineering \& Power Engineering 3, 21-29 (2008)

4. Dunaief, J.: Are Bright Lights Damaging to the Eye?, https://www.brightfocus.org/macular/article/are-bright-lights-damaging-eye. Last accessed 15 March 2020

5. Dunham, R.: Stage Lighting: The Fundamentals. 2nd edn. Routledge, New York (2018)

6. Dunaief, J.: Protect Your Eyes from Bright Lights, Including Blue, https://www.brightfocus.org/macular/article/protect-your-eyes-bright-lights-including-blue. Last accessed 15 March 2020

7. ANSES: Effects of systems using LEDs on human health and the environment, https://www.anses.fr/en/system/files/PRES2019DPA01EN.pdf. Last accessed 20 April 2020

8. ANSES: LEDs \& blue light, https://www.anses.fr/en/content/leds-blue-light. Last accessed 20 April 2020

9. Blender 2.90 Manual. Cycles. Light Paths, https://docs.blender.org/manual/en/dev/render/cycles/render_settings/light_paths.html. Last accessed 17 May 2020

10. SP 31-110-2003. Proektirovanie i montazh elektroustanovok zhilyh i obshestvennyh zdaniy (SP 31-110-2003. Design and installation of electrical devices for residential and public buildings). Kodeks, Saint Petersburg (2004)

11. Prikaz Minkultury RF ot 06.01 .1998 No. 2 "Ob utverzhdenii i vvedenii v deystvie pravil ohrany truda v teatrah i kontsertnyh zalah (Order of the Ministry of Culture of Russia No. 2 "On approval and enforcement of labor protection rules in theaters and concert halls" from January 6, 1998), http://base.garant.ru/6195106/. Last accessed 18 May 2020 